University of South Florida

DIGITAL COMMONS

@ UNIVERSITY OF SOUTH FLORIDA
Digital Commons @ University of

South Florida

$12-1-2011$

\title{
Tracking Costs of Alternatively Fueled Buses in Florida
}

CUTR

Follow this and additional works at: https://digitalcommons.usf.edu/cutr_nctr

\section{Recommended Citation}

"Tracking Costs of Alternatively Fueled Buses in Florida," National Center for Transit Research (NCTR) Report No. CUTR-NCTR-RR-2010-10, Center for Urban Transportation Research, University of South Florida, 2011.

DOI: https://doi.org/10.5038/CUTR-NCTR-RR-2010-10

Available at: https://scholarcommons.usf.edu/cutr_nctr/123

This Technical Report is brought to you for free and open access by the National Center for Transit Research (NCTR) Archive (2000-2020) at Digital Commons @ University of South Florida. It has been accepted for inclusion in Research Reports by an authorized administrator of Digital Commons @ University of South Florida. For more information, please contact digitalcommons@usf.edu. 
Prepared by

National Center for Transit Research

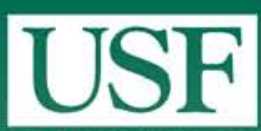

UNIVERSITY OF

SOUTH FLORIDA
Tracking Costs of Alternatively Fueled Buses in Florida

December 2011

Final Report

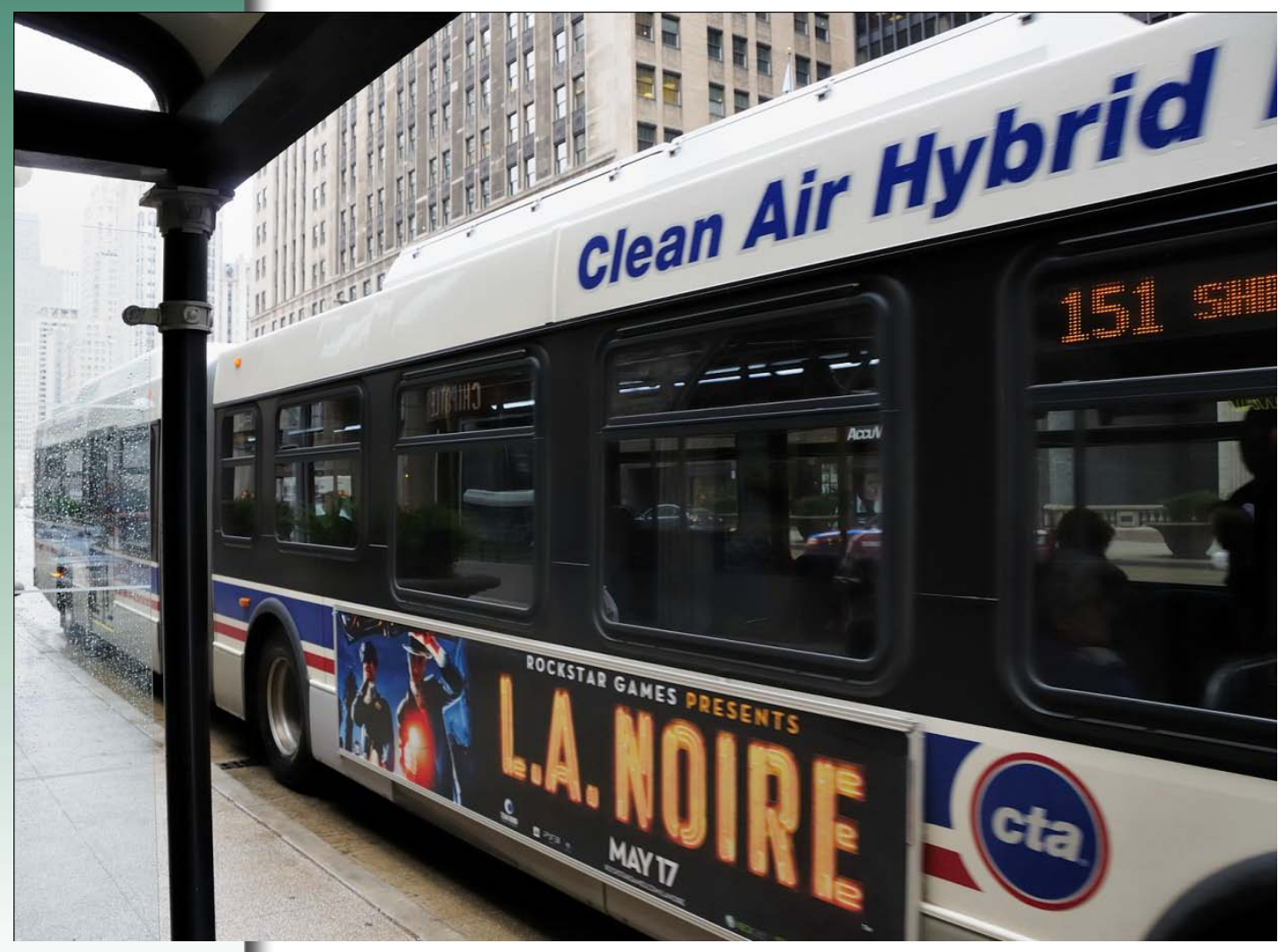

Funded by

Florida Department of Transportation

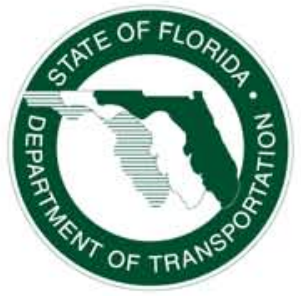




\title{
Tracking Costs of Alternatively Fueled Buses in Florida
}

\author{
Final Report
}

Prepared for

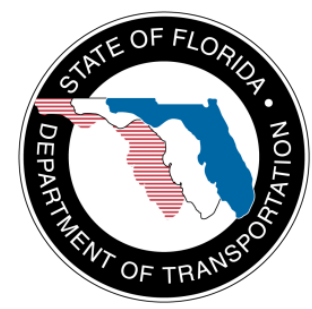

State of Florida Department of Transportation

Public Transit Office

605 Suwannee Street, MS 30

Tallahassee, Florida 32399-0450

Project Manager: Robert E. Westbrook

Prepared by:

Stephen L. Reich, Alexander Kolpakov

\section{NCTR}

National Center for Transit Research

Center for Urban Transportation Research (CUTR)

University of South Florida

4202 East Fowler Avenue, CUT100

Tampa, Florida 33620-5375

December 2011

BDK85 977-18 
Disclaimer

The contents of this report reflect the views of the authors, who are responsible for the facts and the accuracy of the information presented herein. This document is disseminated under the sponsorship of the Department of Transportation University Transportation Centers Program and the Florida Department of Transportation, in the interest of information exchange. The U.S. Government and the Florida Department of Transportation assumes no liability for the contents or use thereof. 


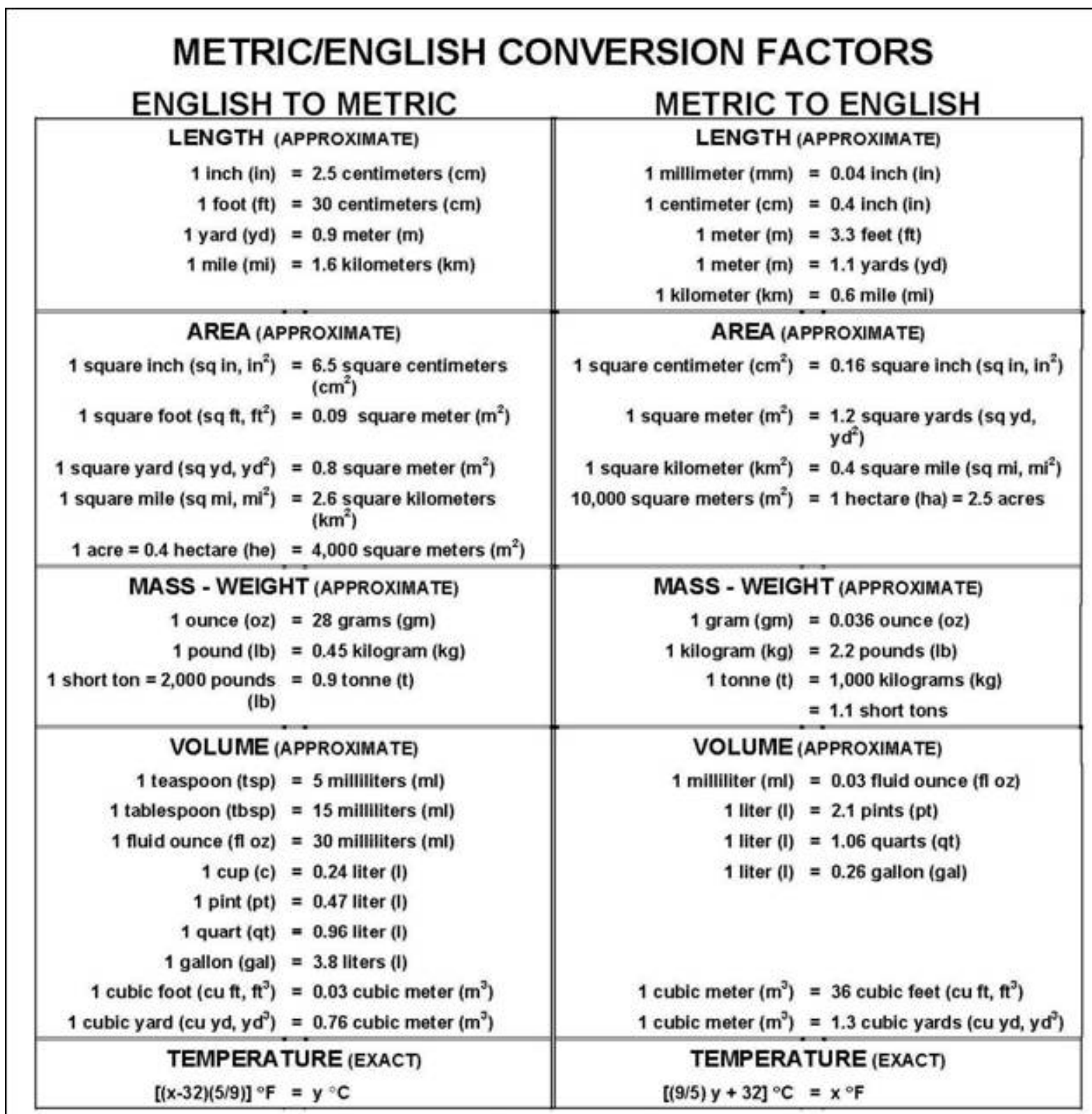

\section{QUICK INCH - CENTIMETER LENGTH CONVERSION}

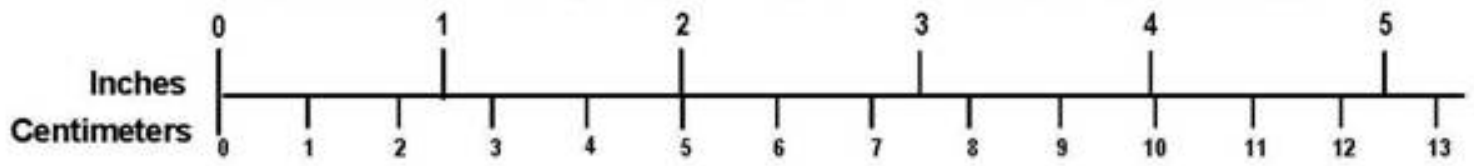

\section{QUICK FAHRENHEIT - CELSIUS TEMPERATURE CONVERSION}

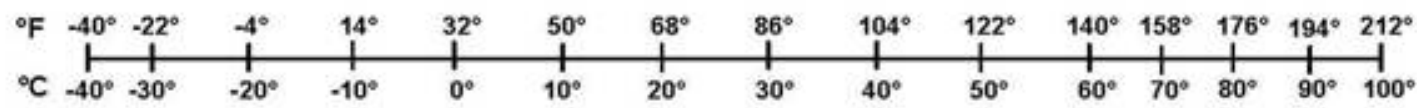

For more exact and or other conversion factors, see NIST Miscellaneous Publication 286. Units of Weights and Measures. 
Technical Report Documentation Page

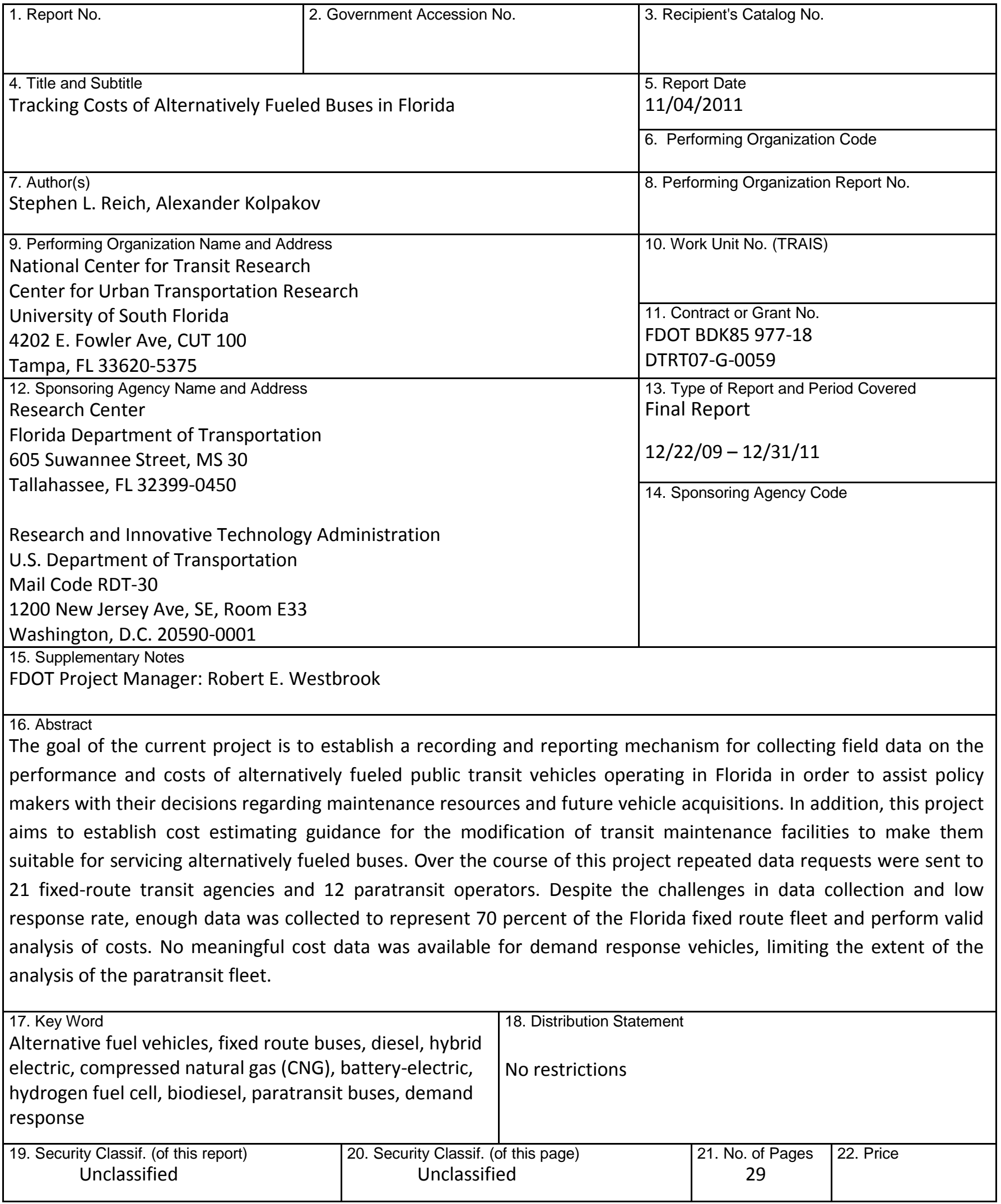

Form DOT F 1700.7 (8-72) Reproduction of completed page authorized 


\title{
Acknowledgements
}

\author{
FDOT Project Manager \\ Robert E. Westbrook \\ Florida Department of Transportation
}

CUTR Project Team

Principal Investigator: Stephen L. Reich

Researcher: Alexander Kolpakov

\author{
Working Group \\ Transportation Program Evaluation and Economic Analysis
}




\section{Executive Summary}

Transit agencies across Florida have been dealing with escalating fuel prices and changes in environmental regulations affecting the use of diesel engines and diesel fuel. In an effort to address rising fuel costs and environmental concerns, many agencies have introduced alternative fuel technologies to their traditional diesel-powered fleets, including biodiesel, compressed natural gas (CNG), hybrid-electric, battery-electric, hydrogen fuel cell, and other technologies. These advancements, however, have resulted in increased capital and operating costs for some fixed-route operators and created challenges for the wide-spread adoption of advanced transit technologies.

With an interest in collecting and evaluating up-to-date data on the performance and cost of alternative fuel vehicles, the Florida Department of Transportation (FDOT) has engaged the Center for Urban Transportation Research (CUTR) at the University of South Florida (USF) to establish a recording and reporting mechanism to capture relevant field data on the performance of alternative fuel transit technologies in Florida. In addition, FDOT was also interested in investigating the approximate cost implications for the modification of transit maintenance facilities to make them suitable for servicing alternative fuel buses.

CUTR has contacted and approached all fixed-route transit agencies in the state with regular data requests. This was arranged through electronic and phone communication in coordination with the project manager. In addition, CUTR researchers also reached out to paratransit operators to collect data on smaller demand response transit vehicles. Unfortunately, regardless of the continued efforts to establish regular data reporting, the response rate to these data requests has been less than ideal.

While CUTR was able to obtain operations and cost data for fixed-route buses from five major transit agencies, representing about 70 percent of the fixed-route fleet in the state, no data were provided for the small demand response vehicles. The only type of data covering paratransit vehicles that were available to CUTR were the inventory of paratransit buses acquired through the statewide vehicle procurement system, Transit Research Inspection Procurement Services (TRIPS). The above challenges limited the amount and the reliability of the analysis that could be performed on this project.

The analysis of data for fixed-route buses revealed that the vast majority of transit buses in Florida (95\% of the reported fleet) are regular diesel buses, while only 5 percent are alternative fuel vehicles (mostly diesel hybrids). Over 88 percent of the diesel buses are 40 -foot buses with 31-foot and 35-foot buses representing 6 percent and 3 percent of the diesel fleet, respectively. Alternative fuel buses, on the other hand, are more likely to be of larger size than diesel buses. Almost half of the hybrid buses are articulated buses, while 40 -foot buses represent approximately 30 percent of the hybrid bus transit fleet.

The analysis of fixed-route data showed that alternative fuel buses have significantly higher acquisition costs (almost double) and slightly better gas mileage, compared to diesel buses. In addition, hybrid buses tend to have lower parts costs and maintenance costs per mile than comparable diesel buses. A 40-foot diesel bus has an average fuel economy of $3.94 \mathrm{mpg}$, parts cost per mile of 21.9 cents, and 
maintenance cost per mile of 23.5 cents, while a typical 40 -foot diesel hybrid bus has fuel economy of $4.03 \mathrm{mpg}$, parts per mile cost of 11.9 cents, and maintenance cost per mile of 15.3 cents.

The analysis of the capital procurement records in the TRIPS database indicate that gasoline-fueled demand response vehicles seem to be more popular than vehicles running on diesel fuel, regardless of whether they were purchased with or without assistance from Federal Transit Administration (FTA). One possible explanation for the agencies' preference of gasoline vehicles over diesel could be due to the lower acquisition costs of gasoline vehicles ( $\$ 72.5$ thousand for gasoline bus versus $\$ 73.7$ thousand for a diesel bus, for the demand response vehicles acquired with federal assistance).

The data showed that 22-foot and 23-foot were, by far, the most popular sizes for the vehicles acquired with FTA assistance. On the other hand, 23-foot and 20-foot buses were the most popular among demand response vehicles acquired without federal assistance, followed by 31-foot and 22-foot vehicles.

Alternative fuel vehicles often require maintenance procedures that are not typical for the vehicles running on traditional fuels and may require certain modifications to transit agencies' maintenance facilities to address additional safety requirements.

The review of the literature indicated that the cost of modifying transit agencies' maintenance facilities to make them suitable for alternative fuel vehicles may run anywhere from $\$ 50,000$ to $\$ 600,000$ for a typical 150- to 200-bus garage. While being highly dependent on the type of alternative fuel and the current design of the facility, these modifications typically involve improvements in ventilation and the fire suppression system, as well as the installation of heat and smoke detectors, explosion-proof electrical wiring and other improvements. In addition, the construction of a fueling facility for alternative fuel vehicles may cost transit agencies anywhere from $\$ 200,000$ to $\$ 2.5$ million, depending on the type of fuel and the scale of operation.

The intent of the current analysis was to contribute to the ongoing evaluation of the costs and benefits of investment in advanced transit technologies rather than provide recommendations on the choice of a particular alternative fuel technology. Additionally, since the analysis was based on a relatively limited data sample, representing one point in time, the reliability may not be particularly high, and the results of the analysis should be treated with caution. As more field data are collected, the reliability of the analysis will improve.

To facilitate data collection, CUTR recommends implementing a web-based reporting system that would allow agencies to input data electronically on a regular basis. It is also recommended that such data reporting becomes a requirement for transit agencies under their grant or funding agreements with FDOT. 


\section{Contents}

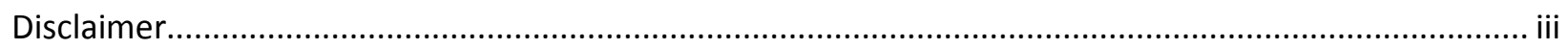

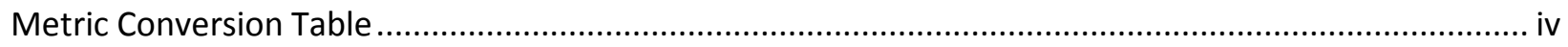

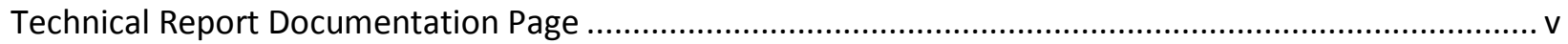

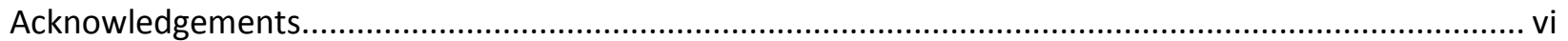

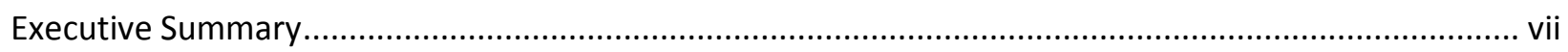

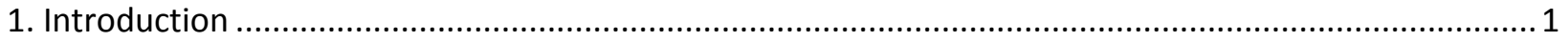

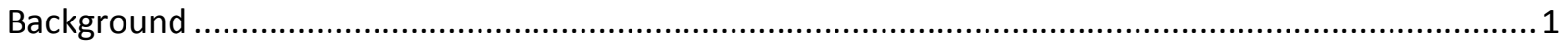

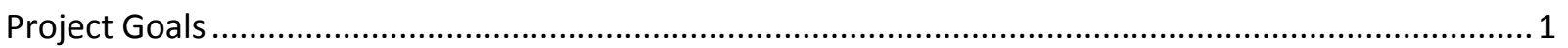

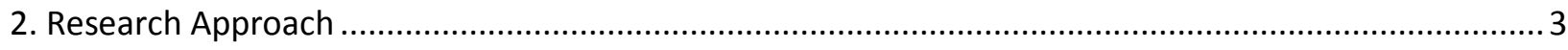

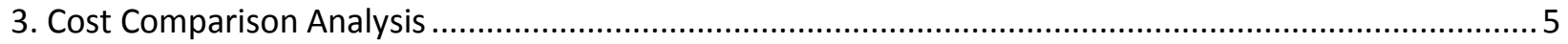

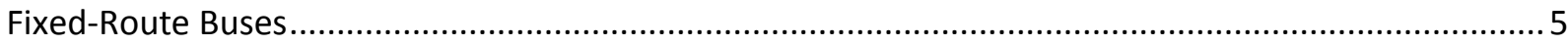

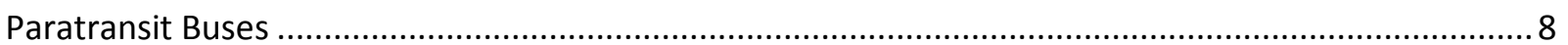

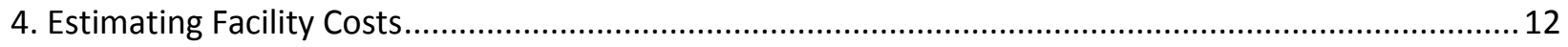

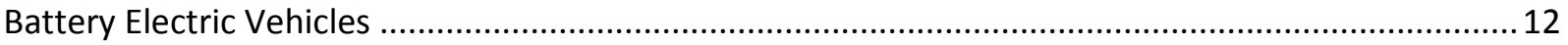

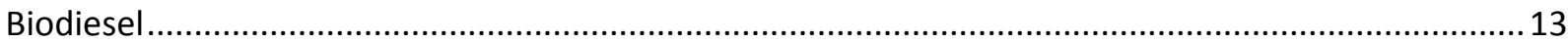

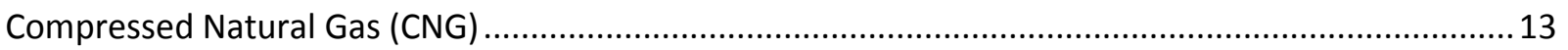

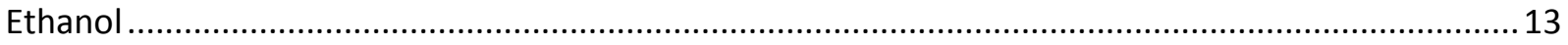

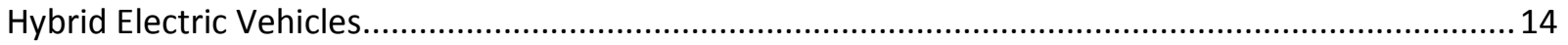

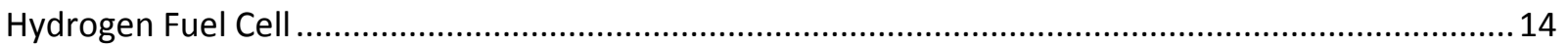

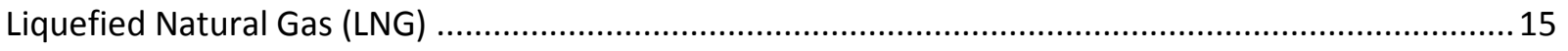

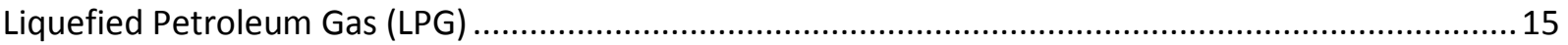

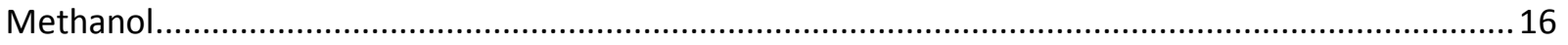

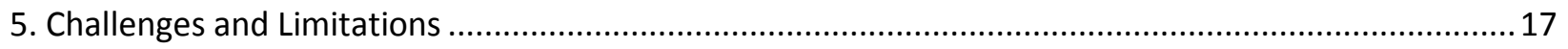

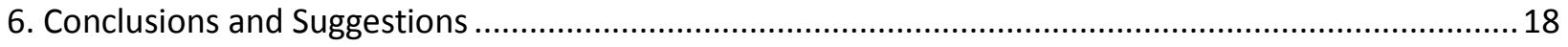

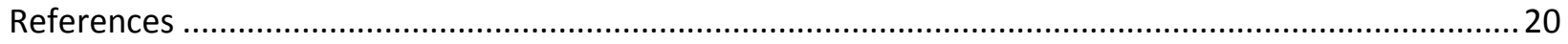




\section{List of Tables}

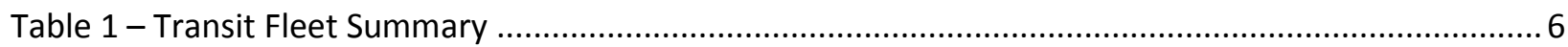

Table 2 - Detailed Cost and Performance Comparison of Transit Fleet................................................ 6

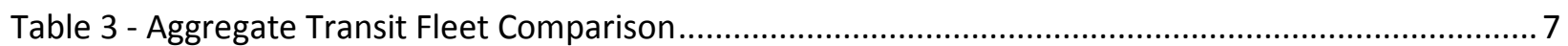

Table 4 - Demand Response Fleet Acquired with FTA's Capital Assistance (Section 5310)....................... 8

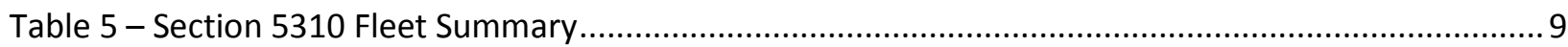

Table 6 - Demand Response Fleet Acquired Without FTA's Assistance (Non-5310) ................................ 9

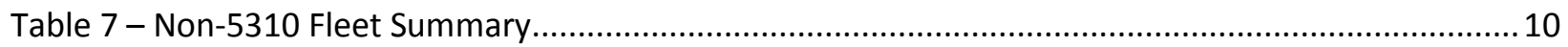

Table 8 - Vehicles Acquired with Federal Assistance by Fuel Type and Vehicle Size ................................10

Table 9 - Non-5310 Paratransit Vehicles by Fuel Type and Vehicle Size................................................. 11 


\section{Introduction}

\section{Background}

Florida transit agencies have been dealing with volatile fuel prices and changes in regulations regarding diesel engines and fuel. In addition, there has been an increased emphasis on reducing the overall consumption of fossil fuels, as well as reducing carbon emissions by transit agencies. To address fuel price uncertainties and environmental concerns, many agencies have introduced alternative fuel vehicles into their fleets. This has occurred even as diesel technology has gotten "cleaner" with recent changes due to ultra-low sulfur fuel and enhanced emission control technologies. These advancements, however, have increased both capital and operating costs for some fixed-route operators and created challenges for the wide-spread adoption of advanced transit technologies.

One technology that is gaining popularity is the diesel hybrid-electric bus. The growth in the acquisition of these units has been helped by recent funding made available through the federal economic stimulus effort. Some agencies in Florida have made applications and are receiving funding for these buses through the "Transit Investments for Greenhouse Gas and Energy Reduction" or TIGGER Grant program while others are using regular transit capital funds. The TIGGER Grants were created as a part of the American Recovery and Reinvestment Act of 2009. Typically, FDOT funds 50 percent of the non-federal share of bus capital and stands to have substantial investment in this technology as acquisition costs for these buses average about $\$ 150,000$ more per unit.

FDOT has requested the professional assistance of the Center for Urban Transportation Research (CUTR) at the University of South Florida (USF) in tracking and reporting the costs associated with acquiring and operating alternative fuel buses by Florida transit agencies. In addition to the lifecycle cost analysis, FDOT has also requested CUTR to investigate the cost implications related to modifying transit fleet maintenance facilities to make them suitable to accommodate alternative fuel vehicles.

The Center for Urban Transportation Research (CUTR), established in 1998, has become nationally recognized and serves as an important resource for policymakers, transportation professionals, the education system, and the public. With an emphasis on developing innovative, implementable solutions to transportation problems, CUTR provides high quality, objective transportation expertise in the form of technical support, policy analysis, and research support that translates directly into benefits to its project sponsors.

\section{Project Goals}

The main objective of the current project is to establish a recording and reporting mechanism for the performance and costs of alternatively fueled public transit vehicles operating in Florida. The data, collected and reported, will enable policy makers to have actual field data to assist in future decision making on maintenance resources and future vehicle acquisitions. Another aim of this project is to establish cost estimating guidance for the modification of transit maintenance facilities to make them suitable for servicing alternatively fueled buses. 
FDOT is interested in collecting and maintaining up-to-date data on the performance and costs of alternative fuel vehicles as both FDOT and local transit agencies continue to evaluate the benefits and costs of investment in the advanced transit technologies.

While the project provides for the evaluation of performance and costs of alternative fuel buses, the primary goal of this effort is to establish a process for the ongoing assessment of alternative fuel transit fleet performance. It is understood that as more data are accumulated the current assessment of alternative fuel transit vehicles' cost efficiency and performance may change. The current analysis is intended to provide decision support for policy makers regarding the costs involved in operating alternative fuel buses in the Florida transit fleet, rather than give definitive recommendations regarding the application of a particular alternative propulsion technology. 


\section{Research Approach}

CUTR worked collaboratively with the FDOT Transit Office to develop a data reporting tool for agencies to use in transmitting information on the costs and reliability of their alternative fuel vehicles. The data collection template was assembled in the form of a brief spreadsheet table, to be filled by the transit operators, covering various parameters of transit vehicles and the historic costs associated with operating them. The reported data included: vehicle number, vehicle length, power plant, fuel type used, duty cycle, date placed in service, vehicle acquisition cost, life-to-date mileage, life-to-date fuel usage, life-to-date labor costs, life-to-date parts costs, warranty status, and other parameters. The tool was designed with the intent to minimize additional data gathering and reporting to the extent possible, while not compromising the project objectives.

Once the data collection tool was finalized, CUTR sent data submission requests to all fixed-route transit agencies in Florida requesting their assistance in collecting the data. Agencies were requested to report on their entire fleet (both alternative and traditionally-fueled), and they were asked to report on a quarterly basis. In addition to the data collection mail-outs, CUTR also followed up with phone calls to the transit agencies to encourage their submissions. Regular reminders to submit operations and maintenance cost data for their fleets were sent to Florida transit agencies in coordination with the project manager. In addition, the principal investigator maintained regular contacts with the transit agencies, addressing their questions and concerns regarding the collection and submission of data.

Regardless of the tremendous efforts put in by CUTR researchers to collect the data, and the requests by the FDOT Project Manager to assist CUTR in this effort, the response to these data requests have been less than ideal. During the whole period of data collection, only five transit agencies provided relevant maintenance and cost data for their fleets, including Broward County Transit, Regional Transit Systems, Miami Dade Transit, Palm Tran, and StarMetro.

These data have been used to update the cost model used for the analysis. Keeping the model current enables performing cost per mile comparisons across alternatively fueled vehicles, which is essential for the current analysis. Despite the low response rate, the data collected covers over 70 percent of the Florida transit fleet, allowing reasonable accuracy in the application of the model. However, the lack of consistent reporting does not provide for an on-going analysis, but rather only allows for a one-time evaluation.

In addition to fixed-route transit agencies, CUTR researchers also made an attempt to collect operating and cost data for paratransit and demand response vehicles operated in Florida. In an effort to facilitate data collection on small transit vehicles, CUTR attended the Florida Paratransit Maintenance Consortium Meeting in Tallahassee in September of 2011. The meeting was mainly designed for maintenance and service managers of small transit/paratransit operators, and also included representatives from FDOT. A brief presentation was made to the participants about the goals of the current project outlining the data requirements. The above effort was coordinated with the project manager, who also attended the meeting. 
After the meeting, CUTR researchers sent the formal data submission request to the attendees of the Paratransit Consortium Meeting, requesting them to provide relevant maintenance and cost data on their paratransit fleet. A total of 12 Florida agencies that operate demand response vehicles were contacted with data requests, including: HART, MV Transit, Lake County Public Transportation, Big Bend Transit, Jtrans, Citrus County Fleet Shop, St. Johns County COA, Levy County Transit, StarMetro, Calhoun County Transit, Neighborly Care, and Fleet Care.

Unfortunately, none of the contacted agencies provided the requested data on their paratransit fleet. Given that no response was received from the contacted agencies, CUTR researched the records of the statewide vehicle procurement system, called TRIPS, to obtain costs and performance data on the small vehicles acquired by Florida transit agencies through that system. Since the data on vehicle operating costs are not reported in the TRIPS database, CUTR was unable to provide any analysis of the costs involved in operating small transit vehicles. The data available through TRIPS could only support the analysis of inventory of Florida paratransit vehicles. Therefore, the analysis of the demand response transit vehicles presented in the current report will be limited to the simple vehicle inventory analysis.

Separate from the operating cost data collection and analysis, CUTR also researched and documented the potential costs associated with modifying transit bus maintenance facilities to accommodate alternatively fueled vehicles. CUTR reviewed previous research, common practices, and other agencies' experience with operating alternative fuel vehicles to identify typical requirements and cost implications related to retrofitting transit maintenance facilities for the safe handling of alternative fuels. The results of this research are presented in the form of a literature review in the following section of this report. 


\section{Cost Comparison Analysis}

CUTR made repeated attempts to collect performance and cost data for both fixed-route and paratransit vehicle fleets. Recognizing the difference between the two types of service, the data collection was performed separately for fixed-route buses and paratransit buses. Consequently, the costs were also reported separately for these two types of transit service.

While CUTR was able to collect operating cost data for about 70 percent of the Florida fixed-route fleet, no such data were available for the demand response vehicles. Therefore, the analysis of the paratransit fleets, presented in this report, is based on the limited amount of information available through the statewide vehicle procurement program called Transit Research Inspection Procurement Services (TRIPS), and only covers the inventory analysis of the state paratransit fleet. In addition, demand response vehicles acquired with federal assistance (Section 5310) are reported separately from the vehicles acquired without federal participation.

\section{Fixed-Route Buses}

The Florida Department of Transportation (FDOT) has engaged CUTR to collect and report performance and cost data related to the operation and maintenance of Florida transit vehicles. Over the course of the project several data requests and data submission reminders were sent to all Florida fixed-route transit agencies, requesting their assistance in the data collection effort. Relevant cost data for the fixed-route service were obtained from the following five transit agencies:

1. Broward County Transit - Broward County

2. RTS - Gainesville

3. MDT - Miami

4. Palm Tran - Palm Beach

5. StarMetro - Tallahassee

While the number of agencies responding was rather low, the data collected from these agencies covers the majority of the transit vehicles in Florida. All the summary statistics presented in this document are based on the cost data from these five transit agencies. The summary of the physical characteristics of the Florida transit fleet is presented in Table 1. 
Table 1 - Transit Fleet Summary

\begin{tabular}{|l|c|c|}
\hline Power Plant & Length & $\begin{array}{c}\text { Number of } \\
\text { Buses }\end{array}$ \\
\hline \multirow{4}{*}{ Diesel } & $29^{\prime}$ & 6 \\
\cline { 2 - 3 } & $30^{\prime}$ & 4 \\
\cline { 2 - 3 } & $31^{\prime}$ & 75 \\
\cline { 2 - 3 } & $33^{\prime}$ & 6 \\
\cline { 2 - 3 } & $35^{\prime}$ & 37 \\
\cline { 2 - 3 } & $40^{\prime}$ & 1,103 \\
\cline { 2 - 3 } & $45^{\prime}$ & 12 \\
\cline { 2 - 3 } & Articulated & 10 \\
\hline \multirow{4}{*}{ Diesel Hybrid } & $33^{\prime}$ & 1 \\
\cline { 2 - 3 } & $40^{\prime}$ & 20 \\
\cline { 2 - 3 } & $41^{\prime}$ & 13 \\
\cline { 2 - 3 } & Articulated & 32 \\
\hline Total Fleet: & & $\mathbf{1 , 3 1 9}$ \\
\hline
\end{tabular}

The vast majority of transit buses in Florida (1,253 buses or $95 \%$ of the reported fleet) are regular diesel buses, while only 5 percent ( 66 buses) are alternative fuel vehicles (diesel hybrids). Over 88 percent of diesel buses are 40-foot buses. Thirty-one-foot and 35-foot buses represent approximately 6 percent and 3 percent of the diesel fleet, respectively. The other types of diesel buses do not exceed 1 percent for each size type. Almost half of all hybrid buses (over 48 percent) are articulated buses, while 40 -foot buses represent approximately 30 percent of the hybrid bus transit fleet.

Detailed gas mileage and cost comparisons for different types of transit buses are presented in Table 2.

Table 2 - Detailed Cost and Performance Comparison of Transit Fleet

\begin{tabular}{|c|c|c|c|c|c|c|c|}
\hline Power Plant & Bus Length & $\begin{array}{l}\text { Number } \\
\text { of Buses }\end{array}$ & $\begin{array}{c}\text { Average } \\
\text { Vehicle } \\
\text { Age (years) }\end{array}$ & $\begin{array}{c}\text { Average } \\
\text { Acquisition } \\
\text { Cost }(\$)^{*}\end{array}$ & $\begin{array}{c}\text { Gas } \\
\text { Mileage } \\
\text { (mpg) }\end{array}$ & $\begin{array}{l}\text { Parts } \\
\text { Cost per } \\
\text { Mile (\$) }\end{array}$ & $\begin{array}{c}\text { Maintenance } \\
\text { Cost per } \\
\text { Mile }(\$)^{*}\end{array}$ \\
\hline \multirow{8}{*}{ Diesel } & $29^{\prime}$ & 6 & 4.1 & $\$ 310,544$ & 3.84 & $\$ 0.102$ & $\$ 0.089$ \\
\hline & $30^{\prime}$ & 4 & 3.7 & $\$ 4,578$ & 14.89 & $\$ 0.180$ & $\$ 0.266$ \\
\hline & $31^{\prime}$ & 75 & 3.2 & $\$ 290,255$ & 4.20 & $\$ 0.220$ & $\$ 0.281$ \\
\hline & $33^{\prime}$ & 6 & 1.9 & $\$ 152,406$ & 5.26 & $\$ 0.141$ & $\$ 0.172$ \\
\hline & $35^{\prime}$ & 37 & 4.3 & $\$ 308,089$ & 3.71 & $\$ 0.157$ & $\$ 0.157$ \\
\hline & $40^{\prime}$ & 1,103 & 6.7 & $\$ 299,153$ & 3.94 & $\$ 0.219$ & $\$ 0.235$ \\
\hline & $45^{\prime}$ & 12 & 4.2 & $\$ 495,245$ & 3.09 & $\$ 0.157$ & $\$ 0.220$ \\
\hline & Articulated & 10 & 2.3 & $\mathrm{~N} / \mathrm{A}$ & 3.22 & $\$ 0.202$ & $\mathrm{~N} / \mathrm{A}$ \\
\hline \multirow{4}{*}{ Diesel Hybrid } & $33^{\prime}$ & 1 & 0.4 & $\mathrm{~N} / \mathrm{A}$ & 22.58 & $\$ 0.047$ & $\$ 0.061$ \\
\hline & $40^{\prime}$ & 20 & 1.9 & $\$ 550,863$ & 4.03 & $\$ 0.119$ & $\$ 0.153$ \\
\hline & $41^{\prime}$ & 13 & 0.1 & $\$ 548,212$ & 4.47 & $\$ 0.058$ & $\$ 0.167$ \\
\hline & Articulated & 32 & 0.3 & $\$ 830,560$ & 4.19 & $\$ 0.043$ & $\$ 0.145$ \\
\hline Total Fleet: & & 1,319 & 6.1 & 315,759 & 3.94 & $\$ 0.217$ & $\$ 0.234$ \\
\hline
\end{tabular}

* Average acquisition costs and maintenance cost per mile are calculated excluding Broward County since these data were not available for Broward. 
The data show that alternative fuel buses have significantly higher acquisition costs and slightly better gas mileage compared to diesel buses. In addition, hybrid buses also tend to have lower parts costs and maintenance costs per mile than comparable diesel buses. For example, a 40 -foot diesel bus has an average fuel economy of $3.94 \mathrm{mpg}$, a parts cost of 21.9 cents/mile, and a maintenance cost of 23.5 cents/mile compared to $4.03 \mathrm{mpg}, 11.9$ cents/mile in parts costs, 15.3 cents/mile in maintenance costs for a 40 -foot diesel hybrid bus.

The difference in gas mileage and parts/maintenance costs for hybrid buses can be, at least partially, attributed to the average age of the vehicles. In addition to being more efficient, hybrid buses are also newer, with an average age of less than a year for most vehicles. For comparison, the average age of diesel buses operated by Florida transit agencies exceeds six years. Newer vehicles typically perform better and can cost less to operate when compared to older vehicles.

The analysis of the data reveals unusually high fuel economy for 30-foot diesel buses (14.89 mpg) and 33-foot hybrid buses ( $22.58 \mathrm{mpg}$ ), as well as unrealistically low acquisition costs for 30 -foot diesel buses $(\$ 4,578$ per vehicle). These anomalies are likely the result of errors in the data reported by the agencies. However, since these inaccuracies only affect a very small number of vehicles in the overall transit fleet data, these outliers do not noticeably skew the overall results of the analysis.

The comparison of performance and maintenance costs between traditional diesel buses and hybrid buses operated by Florida transit agencies, at an aggregate level, is presented in Table 3.

Table 3 - Aggregate Transit Fleet Comparison

\begin{tabular}{|l|r|r|r|r|r|r|}
\hline Power Plant & $\begin{array}{c}\text { Number of } \\
\text { Buses }\end{array}$ & $\begin{array}{c}\text { Average } \\
\text { Vehicle } \\
\text { Age (years) }\end{array}$ & $\begin{array}{c}\text { Average } \\
\text { Acquisition } \\
\text { Cost } \mathbf{( \$ )}\end{array}$ & $\begin{array}{c}\text { Gas Mileage } \\
\text { (mpg) }\end{array}$ & $\begin{array}{c}\text { Parts Cost } \\
\text { per Mile (\$) }\end{array}$ & $\begin{array}{c}\text { Maintenance } \\
\text { Cost per Mile } \\
\text { (\$) }\end{array}$ \\
\hline Diesel & 1,253 & 6.4 & $\$ 299,179$ & 3.94 & $\$ 0.218$ & $\$ 0.235$ \\
\hline Diesel Hybrid & 66 & 0.8 & $\$ 720,569$ & 4.14 & $\$ 0.093$ & $\$ 0.149$ \\
\hline Fleet Total: & $\mathbf{1 , 3 1 9}$ & $\mathbf{6 . 1}$ & $\mathbf{\$ 3 1 5 , 7 5 9}$ & $\mathbf{3 . 9 4}$ & $\mathbf{\$ 0 . 2 1 7}$ & $\mathbf{\$ 0 . 2 3 4}$ \\
\hline
\end{tabular}

* Average acquisition costs and maintenance cost per mile are calculated excluding Broward County since these data were not available for Broward.

The data show that hybrid buses have 5 percent better fuel economy, 57 percent lower parts cost per mile, and 36 percent lower maintenance costs per mile compared to regular diesel buses. At the same time, hybrid buses cost more than double than that of diesel vehicles.

These results, however, should be interpreted with caution since hybrid buses are much newer vehicles (with an average age of less than a year), and some of the cost differential could be attributed to that rather than the differences in performance of different power plants (diesel vs. hybrid). In addition, the estimates for hybrid buses are based on a very limited number of data points, limiting the robustness of the analysis. As more data are collected on the performance and maintenance costs of alternative fuel transit vehicles, the reliability of the analysis will improve. 


\section{Paratransit Buses}

The TRIPS database contains records of the demand response vehicles that were acquired both with and without federal assistance. Paratransit vehicles acquired with federal participation are typically funded by the FTA's capital program under Section 5310. Title 49 U.S.C. 5310 authorizes the capital assistance program for the special needs of elderly individuals and individuals with disabilities. FTA refers to this formula program as the Section 5310 Program. Table 4 presents the summary of the data, extracted from the TRIPS vehicle procurement system, on demand response vehicle fleets acquired through the Section 5310 capital assistance program.

Table 4 - Demand Response Fleet Acquired with FTA's Capital Assistance (Section 5310)

\begin{tabular}{|c|c|c|c|}
\hline Year & Fuel & $\begin{array}{c}\text { Quantity of } \\
\text { Vehicles }\end{array}$ & $\begin{array}{c}\text { Average } \\
\text { Acquisition Cost }\end{array}$ \\
\hline \multirow{4}{*}{2007} & Diesel & 39 & $\$ 82,112$ \\
\hline & Gas & 42 & $\$ 72,973$ \\
\hline & Unknown & 4 & $\$ 69,154$ \\
\hline & All 2007 Fleet: & 85 & $\$ 76,986$ \\
\hline \multirow{4}{*}{2008} & Diesel & 74 & $\$ 77,892$ \\
\hline & Gas & 128 & $\$ 58,967$ \\
\hline & Unknown & 1 & $\$ 39,125$ \\
\hline & All 2008 Fleet: & 203 & $\$ 65,477$ \\
\hline \multirow{4}{*}{2009} & Diesel & 271 & $\$ 76,496$ \\
\hline & Gas & 431 & $\$ 70,021$ \\
\hline & Unknown & 11 & $\$ 54,714$ \\
\hline & All 2009 Fleet: & 713 & $\$ 72,246$ \\
\hline \multirow{4}{*}{2010} & Diesel & 12 & $\$ 124,163$ \\
\hline & Gas & 145 & $\$ 60,720$ \\
\hline & Unknown & 22 & $\$ 227,577$ \\
\hline & All 2010 Fleet: & 179 & $\$ 85,481$ \\
\hline \multirow{4}{*}{2011} & Diesel & 20 & $\$ 88,605$ \\
\hline & Gas & 161 & $\$ 66,339$ \\
\hline & Unknown & 4 & $\$ 72,846$ \\
\hline & All 2011 Fleet: & 185 & $\$ 68,886$ \\
\hline Unknown & Unknown & 150 & $\$ 71,322$ \\
\hline \multicolumn{2}{|c|}{ Total Paratransit Fleet: } & 1,515 & $\$ 72,667$ \\
\hline
\end{tabular}

The data presented in Table 4 shows that transit agencies purchase more demand response vehicles that run on gas rather than on diesel fuel. The analysis of TRIPS data indicates that there are currently twice as many gas vehicles acquired with FTA assistance than there are vehicles running on diesel fuel. Looking at the annual purchases for the period of 2007 through 2011, reveals the trend of an increasing percentage of gasoline-powered vehicles in the overall purchases. While in 2007, purchases of dieseland gasoline- powered vehicles were approximately split fifty-fifty, there were eight times more gasoline vehicles purchased than diesel in 2011. One possible explanation for the agencies' preference of 
gasoline vehicles over diesel could be due to the lower acquisition cost of gasoline vehicles. Other potential factors could include differences in operating costs, maintenance costs, reliability, etc. A summary of the comparison between diesel and gasoline vehicles is presented in Table 5.

Table 5 - Section 5310 Fleet Summary

\begin{tabular}{|l|r|r|}
\hline \multicolumn{1}{|c|}{ Fuel Type } & $\begin{array}{c}\text { Number of } \\
\text { Vehicles }\end{array}$ & $\begin{array}{c}\text { Average } \\
\text { Acquisition Cost }\end{array}$ \\
\hline Diesel & 416 & $\$ 73,684$ \\
\hline Gas & 907 & $\$ 72,540$ \\
\hline Unknown & 192 & $\$ 72,401$ \\
\hline
\end{tabular}

The summary of the Florida demand response fleet, listed in the TRIPS database, acquired without federal assistance is presented in Table 6.

Table 6 - Demand Response Fleet Acquired Without FTA's Assistance (Non-5310)

\begin{tabular}{|c|c|c|c|}
\hline Year & Fuel & $\begin{array}{c}\text { Quantity of } \\
\text { Vehicles }\end{array}$ & $\begin{array}{c}\text { Average } \\
\text { Acquisition Cost }\end{array}$ \\
\hline \multirow{4}{*}{2007} & Diesel & 66 & $\$ 90,924$ \\
\hline & Gas & 236 & $\$ 57,683$ \\
\hline & Unknown & 6 & $\$ 38,220$ \\
\hline & All 2007 Fleet: & 308 & $\$ 64,427$ \\
\hline \multirow{3}{*}{2008} & Diesel & 372 & $\$ 97,420$ \\
\hline & Gas & 311 & $\$ 66,619$ \\
\hline & All 2008 Fleet: & 683 & $\$ 83,395$ \\
\hline \multirow{4}{*}{2009} & Diesel & 353 & $\$ 96,617$ \\
\hline & Gas & 775 & $\$ 71,741$ \\
\hline & Unknown & 2 & $\$ 172,463$ \\
\hline & All 2009 Fleet: & 1,130 & $\$ 79,690$ \\
\hline \multirow{4}{*}{2010} & Diesel & 259 & $\$ 165,662$ \\
\hline & Gas & 501 & $\$ 55,261$ \\
\hline & Unknown & 1 & $\$ 40,138$ \\
\hline & All 2010 Fleet: & 761 & $\$ 92,815$ \\
\hline \multirow{4}{*}{2011} & Diesel & 220 & $\$ 88,236$ \\
\hline & Gas & 541 & $\$ 71,415$ \\
\hline & Unknown & 16 & $\$ 490,000$ \\
\hline & All 2011 Fleet: & 777 & $\$ 84,604$ \\
\hline \multirow{3}{*}{ Unknown } & Diesel & 9 & $\$ 154,351$ \\
\hline & Unknown & 268 & $\$ 64,640$ \\
\hline & All Unknown: & 277 & $\$ 67,555$ \\
\hline \multicolumn{2}{|c|}{ Total Paratransit Fleet: } & 3,936 & 81,749 \\
\hline
\end{tabular}


The data presented in Table 6 shows similar trends that were observed for the paratransit fleet acquired with FTA assistance. Gasoline-fueled vehicles seem to be more popular than vehicles running on diesel fuel, regardless of whether the vehicles were purchased with or without FTA assistance. There are almost twice as many gasoline vehicles acquired without federal assistance than there are diesel vehicles. The price differential between gasoline and diesel vehicles is more noticeable for the vehicles acquired without FTA capital assistance. The summary of the Non-5310 paratransit fleet is presented in Table 7.

Table 7 - Non-5310 Fleet Summary

\begin{tabular}{|l|r|r|}
\hline \multicolumn{1}{|c|}{ Fuel Type } & $\begin{array}{c}\text { Number of } \\
\text { Vehicles }\end{array}$ & $\begin{array}{c}\text { Average } \\
\text { Acquisition Cost }\end{array}$ \\
\hline Diesel & 1,279 & $\$ 83,000$ \\
\hline Gas & 2,364 & $\$ 80,899$ \\
\hline Unknown & 293 & $\$ 83,146$ \\
\hline
\end{tabular}

Paratransit vehicles listed in the TRIPS database typically range in size from 17 to 31 feet. The data shows that 22-foot and 23-foot were, by far, the most popular sizes for the vehicles acquired with FTA assistance. For diesel-powered vehicles the most widely used size was 23-foot, followed by 22-foot. This was not the case for gasoline-powered vehicles. Twenty-two-foot buses comprised the largest share of gasoline-powered paratransit fleet, followed by 26 -foot, and 23-foot vehicles. A more detailed summary of the demand response fleet acquired under FTA's Section 5310, by vehicle size and fuel type, is presented in Table 8.

Table 8 - Vehicles Acquired with Federal Assistance by Fuel Type and Vehicle Size

\begin{tabular}{|c|r|r|r|r|}
\hline $\begin{array}{c}\text { Vehicle Size } \\
\text { (Feet) }\end{array}$ & \multicolumn{5}{|c|}{ Number of Vehicles } \\
\cline { 2 - 5 } & \multicolumn{1}{|c|}{ Diesel } & \multicolumn{1}{|c|}{ Gas } & \multicolumn{1}{c|}{ Unknown } & \multicolumn{1}{c|}{ All Fuels } \\
\hline $17^{\prime}$ & 4 & 103 & 12 & $\mathbf{1 1 9}$ \\
\hline $20^{\prime}$ & 14 & 87 & 39 & $\mathbf{1 4 0}$ \\
\hline $22^{\prime}$ & 90 & 262 & 15 & $\mathbf{3 6 7}$ \\
\hline $23^{\prime}$ & 208 & 149 & 71 & $\mathbf{4 2 8}$ \\
\hline $25^{\prime}$ & 16 & 27 & 12 & $\mathbf{5 5}$ \\
\hline $26^{\prime}$ & 34 & 227 & 7 & $\mathbf{2 6 8}$ \\
\hline $27^{\prime}$ & 17 & 33 & 9 & $\mathbf{5 9}$ \\
\hline $29^{\prime}$ & 9 & & 1 & $\mathbf{1 0}$ \\
\hline $31^{\prime}$ & 24 & 5 & 22 & $\mathbf{5 1}$ \\
\hline Unknown & & 14 & 4 & $\mathbf{1 8}$ \\
\hline Total: & $\mathbf{4 1 6}$ & $\mathbf{9 0 7}$ & $\mathbf{1 9 2}$ & $\mathbf{1 , 5 1 5}$ \\
\hline
\end{tabular}

The analysis of the Non-5310 fleet indicates that 23-foot and 20-foot buses were the most popular among demand response vehicles acquired without federal assistance, followed by 31-foot and 22-foot vehicles. Thirty-one-foot was the most widely used size of the diesel-powered vehicles, followed by $20-$ foot and 23-foot buses. For gasoline-powered buses, the most widely used size were 23-foot vehicles, 
followed by 20 -foot and 22 -foot vehicles. A more detailed summary of the Non-5310 paratransit fleet, by fuel type and vehicle size, is presented in Table 9.

Table 9 - Non-5310 Paratransit Vehicles by Fuel Type and Vehicle Size

\begin{tabular}{|c|r|r|r|r|}
\hline $\begin{array}{c}\text { Vehicle Size } \\
\text { (Feet) }\end{array}$ & \multicolumn{5}{|c|}{ Number of Vehicles } \\
\cline { 2 - 5 } & \multicolumn{1}{|c|}{ Diesel } & \multicolumn{1}{|c|}{ Gas } & \multicolumn{1}{c|}{ Unknown } & \multicolumn{1}{c|}{ All Fuels } \\
\hline $17^{\prime}$ & 1 & 116 & 30 & $\mathbf{1 4 7}$ \\
\hline $18^{\prime}$ & & 1 & & $\mathbf{1}$ \\
\hline $20^{\prime}$ & 388 & 288 & 108 & $\mathbf{7 8 4}$ \\
\hline $22^{\prime}$ & 62 & 267 & 18 & $\mathbf{3 4 7}$ \\
\hline $23^{\prime}$ & 350 & 520 & 105 & $\mathbf{9 7 5}$ \\
\hline $25^{\prime}$ & 5 & & & $\mathbf{5}$ \\
\hline $26^{\prime}$ & 29 & 28 & 11 & $\mathbf{6 8}$ \\
\hline $27^{\prime}$ & 2 & 4 & & $\mathbf{6}$ \\
\hline $29^{\prime}$ & 1 & & & $\mathbf{1}$ \\
\hline $31^{\prime}$ & 423 & 24 & 5 & $\mathbf{4 5 2}$ \\
\hline Unknown & 18 & 1,116 & 16 & $\mathbf{1 , 1 5 0}$ \\
\hline Total: & $\mathbf{1 , 2 7 9}$ & $\mathbf{2 , 3 6 4}$ & $\mathbf{2 9 3}$ & $\mathbf{3 , 9 3 6}$ \\
\hline
\end{tabular}




\section{Estimating Facility Costs}

Alternative fuel transit vehicles often require maintenance procedures that are not typical for vehicles running on traditional fuels. The introduction of alternative fuel vehicles to Florida transit fleets may require certain modifications to transit agencies' maintenance facilities in order to address additional safety requirements associated with alternative fuels. Whenever possible, transit agencies would have to try to modify the existing maintenance facility that could be shared with traditional-fueled vehicles rather than build new facilities exclusively for maintaining alternative fuel vehicles. These modifications can vary significantly, from minor to extensive, depending on the type of fuel used, and the specific circumstances of an individual agency.

In addition, many transit agencies typically have their own fueling facility on site. Building a dedicated fueling facility represents an additional capital cost to the transit agencies operating alternative fuel vehicles in their fleets.

The following section will discuss the common fleet maintenance requirements for different alternative fuels and will present rough cost estimates for modifying transit agencies' service and maintenance facilities. The data on the additional capital cost required for upgrading maintenance facilities to accommodate alternative fuel transit vehicles are very limited and rather dated. However, it can still provide ballpark numbers for the expected costs of the facilities' conversion. Since the cost estimates provided in this section are generalized, and are based on historic costs encountered by other transit agencies in the past they should be treated accordingly and interpreted with caution.

The costs of maintenance facilities' modifications and the construction of fueling facilities for each fuel type are briefly summarized below.

\section{Battery Electric Vehicles}

The main considerations in vehicle maintenance, when compared to regular diesel buses, are related to handling batteries and high-voltage electrical cables in battery-electric and hybrid-electric buses. The regular fire protection construction standards for vehicle storage, motor fuel dispensing facilities, and repair garages (National Fire Protection Association codes: $88 \mathrm{~A}, 30 \mathrm{~A}$ ) is applicable to the battery-electric and hybrid-electric bus maintenance facilities. In addition, it is recommended that the garage also conform to the requirements of NFPA 70 regarding the safe installation and handling of high-voltage electrical wiring and equipment. ${ }^{1}$

Battery storage and charging locations should be well ventilated to ensure that gasses emitting from the battery cells during charging are quickly evacuated from the building. Battery storage racks should be grounded to eliminate the possibility of a short in the circuit. It is also recommended to install smoke and heat detectors near the charging locations that would trigger an automatic shut-off of a charging unit if the temperature exceeds a maximum safe limit. The agencies performing maintenance on battery-electric and hybrid-electric transit vehicles would need to upgrade their facilities' fire detection and suppression systems to be compatible with electric fires. This is especially relevant for the systems installed near battery charging stations in the maintenance facility. 


\section{Biodiesel}

Since biodiesel is simply diesel fuel produced from biological sources (soybeans, vegetable oils, animal fats, etc.) no modifications to maintenance facilities are necessary to accommodate biodiesel-transit vehicles.

\section{Compressed Natural Gas (CNG)}

Transit agencies that operate CNG buses in their fleet typically need to modify their maintenance facility to include proper ventilation, gas leak detection and fire suppression systems. Ventilation rates in the CNG maintenance facility should be high enough to disperse potential gas leaks, and should generally be at least equal to six air exchanges per hour. It is also recommended to design the system in such a way that the ventilation rate would increase upon detection of a leak. ${ }^{2}$ Since natural gas is lighter than air it will tend to accumulate below the ceiling in case of a leak, therefore, roof ventilators are recommended.

Estimating the costs of modifying maintenance facilities is complicated since there are no generally accepted codes and building standards for CNG garages. The modifications may vary substantially depending on the size of the fleet, individual needs, and other characteristics of the agency. For example, SunLine Transit (Thousand Palms, CA) reported spending $\$ 320,000$ for modifying their facilities to accommodate CNG buses, while Los Angeles Metropolitan Transit Authority (Los Angeles, CA) spent about $\$ 1$ million for that purpose. According to the FTA, in 1998, the average cost to modify one dieselfleet maintenance garage for CNG buses was around $\$ 600,000 .^{3}$

The agencies operating CNG buses generally prefer to invest in their own fueling stations, although the use of commercially available CNG facilities is also possible for smaller fleets. The costs to construct new CNG fast-fill fueling stations may vary from hundreds of thousands to millions of dollars, depending on the fueling capacity of the station. For example, Pierce Transit Authority (Lakewood, WA) spent about $\$ 950,000$ for constructing a CNG fueling facility, while New York City Transit (New York City, NY) reported an approximate cost of $\$ 5$ million (1998). FTA estimates that an average CNG fueling station for a typical 200-bus transit fleet will cost approximately $\$ 1.7$ million (1998).

\section{Ethanol}

Ethanol is more volatile than diesel fuel. Thus, the design of maintenance facilities should ensure adequate ventilation systems to provide enough air flow to disperse any potential gas leaks quickly and efficiently. Since ethanol vapor is heavier than air and tends to stay close to the ground, it is recommended to install classified (explosion-proof) electrical wiring at elevations lower than 18 inches above floor level in ethanol vehicle maintenance facilities. In general, maintenance facilities' requirements for ethanol buses are similar to that of methanol vehicles.

It is estimated that modifying a typical maintenance facility for a 200-bus fleet, to address specific requirements of the ethanol vehicles, will cost, on average, $\$ 300,000$ (1998). In addition, modifying one fueling station to make it suitable for ethanol fueling can cost approximately $\$ 400,000$ (1998). A later assessment, however, estimates a much lower cost. The National Renewable Energy Laboratory (NREL) 
surveyed the existing gas stations that implemented ethanol conversions and estimated an average cost for converting the tank to accommodate E-85 to be approximately $\$ 21,000 .{ }^{4}$ As with other fuel types, costs may vary significantly depending on the desired capacity of the facility and the individual circumstances of transit agencies.

\section{Hybrid Electric Vehicles}

Maintenance of hybrid-electric buses involves changing batteries approximately every three years. Transit agencies operating such vehicles may need to upgrade their maintenance facilities with lifts and cranes to handle the replacement of battery packs. In addition, the older lead acid batteries need to be reconditioned every few months. For example, New York City Transit reported reconditioning the batteries of their hybrid buses every six months. ${ }^{5}$ The charging/conditioning equipment can cost up to $\$ 50,000$ to purchase. Reconditioning, however, is only required for lead acid batteries. The newer nickel metal hydride batteries do not require reconditioning.

Battery storage and charging stations for charging several batteries at a time should be ventilated and equipped with heat and smoke detectors to prevent overheating and the build-up of dangerous gasses emitting from the battery during charging.

The upgrades to the maintenance facilities may also include additional safety equipment required for high-voltage electrical systems. Since the electrical systems of regular diesel buses are low-voltage, a typical maintenance garage may not be equipped to perform maintenance on high-voltage vehicle systems native to hybrid buses. No reliable cost estimates for implementing these modifications to the bus maintenance facilities to accommodate hybrid electric buses could be found in the literature.

Hybrid buses use the same fueling infrastructure as regular diesel buses. Thus, no fueling facility modifications will be needed.

\section{Hydrogen Fuel Cell}

While transit agencies often share existing diesel maintenance facilities with alternative fuel buses in their fleet, this setup may not be ideal for servicing hydrogen-powered buses. Many maintenance facility requirements for the hydrogen fleet will be similar to CNG buses. Thus, upgrades to maintenance facilities will need to include gas leak sensors, explosion-proof wiring and improved ventilation of the maintenance areas. The agencies are advised to develop strategies to direct hydrogen away from potential ignition sources, eliminate the use of open flame equipment, and limit the use of hot element electrical heaters. ${ }^{6}$

Hydrogen is much lighter than air and it will tend to rise in the case of a leak and stay close to the ceiling. Ventilation strategies should take that property into account, providing for the fast evacuation of the gas below the ceiling. In general, an indoor maintenance facility used for servicing hydrogen-powered buses is recommended to have air ventilation rates in excess of six air changes per hour, higher than what would normally be required for a repair facility. Ideally, ventilation should be designed in such a way that would direct any hydrogen leak to the outside of the building without being dispersed in the 
maintenance facility (e.g., use movable hoods at each bus bay during maintenance). It may also be prudent to design the facility in such a way that would allow electrical grounding of each hydrogen bus when it's parked for a long time.

Since fuel-cell buses are still very rare, little field data are available on the costs of maintenance facilities' modifications.

Fueling facilities for fuel-cell buses will vary dramatically depending on whether hydrogen is stored on board of the vehicle in a compressed state or generated by an on-board reformer from other fuels. The cost estimates for hydrogen fueling facilities vary dramatically and are usually based on a very limited number of observations.

\section{Liquefied Natural Gas (LNG)}

LNG is produced from natural gas by cooling it to the point where it turns into a liquid state. LNG leaks are slightly different from CNG leaks. Since LNG vapor is initially colder and heavier than air, it tends to stay low (close to floor) in case of a leak, and rises only after it warms up to ambient temperature. Thus, it is recommended to install only classified (explosion-proof) electrical wiring and equipment in all maintenance facility work areas at elevations less than 18 inches above the floor.

Essentially the same safety requirements applicable to CNG fleets will be relevant to the LNG maintenance facilities. Unlike CNG, however, there is very limited data on modifying maintenance facilities to accommodate LNG buses. Therefore, the estimates costs for garage modification may not be very accurate and reliable. The Transit Cooperative Research Program (TCRP) estimates that the median cost of modifying transit maintenance facilities to accommodate LNG fleets is approximately $\$ 600,000$ (1998) for a 150-200-bus garage.

The cost of building a LNG fueling facility can vary depending on capacity desired and other circumstances. However, the average cost of designing and constructing a LNG fueling station is estimated to be approximately $\$ 2.5$ million, with an additional $\$ 200,000$ for the capability to fuel with both LNG and CNG (1998).

\section{Liquefied Petroleum Gas (LPG)}

The use of propane-transit vehicles requires certain modifications to the existing maintenance and fueling facilities. There are specific LPG safety requirements that are not relevant to traditional-fuel fleet. For example, propane storage and dispensing facilities must be located at a certain minimum safe distance from buildings, streets, underground tanks, etc. The upgrades to the maintenance facility should include: explosion-proof wiring and electrical equipment in the areas where propane buses are maintained, flammable gas detectors to warn about dangerous concentrations of gasses (in case of a leak), a higher rate of ventilation compared to diesel garages, and other modifications. While these costs can vary substantially depending on the individual needs of the transit agency, it is estimated that the average cost of modifying a typical 200-bus maintenance facility to accommodate LPG buses is about $\$ 300,000$ (1998). 
While smaller transit agencies may be able to use commercially available LPG fueling stations, larger agencies would typically prefer to have their own fueling facility for their fleet. An average construction cost for one propane fueling facility is approximately $\$ 700,000$ (1998).

\section{Methanol}

Operating methanol transit fleets may require additional capital investments in maintenance and fueling facilities. Since methanol is more volatile than diesel fuel, maintenance facilities for methanol buses should be designed in such a way to eliminate possible ignition source gases and ensure adequate ventilation of the main maintenance areas. In general, maintenance facility requirements for methanol buses are similar to that of ethanol vehicles.

It is estimated that modifying a typical maintenance facility for a 200-bus fleet, to address the requirements of the methanol vehicles, will cost an average of $\$ 300,000$ (1998). In addition, modifying one fueling station to make it suitable for fueling transit buses with methanol can cost approximately $\$ 400,000$ (1998). As with other fuel types, costs may vary significantly depending on the desired capacity of the facility and the individual circumstances of transit agencies. 


\section{Challenges and Limitations}

The greatest challenge in performing the analysis was related to the availability of the data. Only five of the Florida fixed-route transit agencies provided data on the performance and operating costs of their fleet. CUTR was also unable to establish periodic ongoing data collection (on a quarterly basis) as was initially envisioned. In addition, the collected data revealed a rather limited number of alternative fuel vehicles in the Florida transit fleet. The low number of observations limits the reliability of the analysis, and should be interpreted with caution.

While CUTR was able to obtain a limited amount of data on fixed-route buses, no operating and cost data were provided for small-demand-response vehicles. The only type of data covering paratransit vehicles available to CUTR were the inventory of paratransit buses, acquired through the statewide vehicle procurement system - TRIPS. In addition to the lack of operating cost data, none of the 5,400 demand-response vehicles listed in TRIPS database were powered by alternative fuels. The lack of relevant data made it unfeasible to make any estimates regarding the lifecycle costs of operating alternative fuel paratransit vehicles in Florida.

The above challenges limited the amount, and the reliability, of the analysis that could be performed on this project. The results of the analysis presented in this report should be treated with caution, recognizing that it is based on a rather limited amount of data. As more data on the performance and maintenance costs of alternative fuel vehicles, both fixed-route and demand-response becomes readily available, the reliability and robustness of the analysis will improve. 


\section{Conclusions and Suggestions}

Despite the challenges with data availability and the low response rate from the transit agencies, CUTR was able to collect valid operating and maintenance cost data for about 70 percent of the Florida fixedroute transit fleet. The analysis of data for fixed-route buses revealed that the vast majority of transit buses in Florida (95\% of the reported fleet) are regular diesel buses, while only 5 percent are alternative fuel vehicles (mostly diesel hybrids). Over 88 percent of the diesel buses are 40 -foot buses with 31-foot and 35-foot buses representing 6 percent and 3 percent of the diesel fleet, respectively. Alternative fuel buses, on the other hand, are more likely to be larger in size than diesel buses. Almost half of the hybrid buses are articulated buses, while 40 -foot buses represent approximately 30 percent of the hybrid bus transit fleet.

The analysis of fixed-route data showed that alternative fuel buses have significantly higher acquisition costs and slightly better gas mileage, compared to diesel buses. In addition, hybrid buses tend to have lower parts costs and maintenance costs per mile than comparable diesel buses. A 40-foot diesel bus has an average fuel economy of $3.94 \mathrm{mpg}$, a parts cost per mile of 21.9 cents, and a maintenance cost per mile of 23.5 cents, while a typical 40 -foot diesel hybrid bus has fuel economy of $4.03 \mathrm{mpg}$, a parts per mile cost of 11.9 cents, and a maintenance cost per mile of 15.3 cents.

The aggregate comparison of performance and maintenance costs of traditional diesel buses and hybrid buses, operated by Florida fixed-route agencies, revealed that hybrid buses have 5 percent better fuel economy, a 57 percent lower parts cost per mile, and a 35 percent lower maintenance cost per mile, compared to diesel buses. Hybrid buses, on average, cost more than double what the traditional diesel buses cost.

The analysis of the capital procurement records in the TRIPS database indicate that gasoline-fueleddemand response vehicles seem to be more popular than vehicles running on diesel fuel, regardless of whether they were purchased with or without FTA assistance. The trend of the increasing preference of gasoline-powered vehicles over time is more pronounced for vehicles acquired with federal assistance. While in 2007, diesel- and gasoline-powered paratransit vehicles purchased with federal assistance were split approximately fifty-fifty, the purchases of gasoline vehicles in 2011 outnumbered diesel vehicle purchases at a ratio of eight-to-one. One possible explanation for the agencies' preference of gasoline vehicles over diesel could be due to the lower acquisition costs of gasoline vehicles. The average acquisition cost, recorded in the TRIPS database, for a gasoline-powered bus was $\$ 72,500$ versus $\$ 73,700$ for a diesel bus, for the demand-response vehicles acquired with federal assistance. The price differential is more noticeable for vehicles acquired without FTA capital assistance $(\$ 80,900$ for a gasoline vehicle versus $\$ 83,000$ thousand for diesel).

The data shows that 22-foot and 23-foot were, by far, the most popular sizes for the vehicles acquired with FTA assistance. On the other hand, 23-foot and 20-foot buses were the most popular among demand-response vehicles acquired without federal assistance, followed by 31-foot and 22-foot vehicles. 
Alternative fuel vehicles often require maintenance procedures that are not typical for the vehicles running on traditional fuels and may require certain modifications to transit agencies' maintenance facilities to address additional safety requirements. These modifications typically involve improvements in their ventilation and fire suppression systems, as well as the installation of heat and smoke detectors, explosion-proof electrical wiring and other improvements.

The review of the literature indicated that the cost of these modifications may run anywhere from $\$ 50,000$ to $\$ 600,000$ for a typical $150-200$-bus garage and is highly dependent on the type of alternative fuel and the current design of the facility. In addition, the construction of a fueling facility for alternative fuel vehicles may cost transit agencies anywhere from $\$ 200,000$ to $\$ 2.5$ million, depending on the type of fuel and the scale of operation.

The intent of the current analysis was to contribute to the ongoing evaluation of the costs and benefits of investment in advanced transit technologies rather than to provide recommendations on the choice of a particular alternative fuel technology. No attempt was made to provide a comprehensive comparative analysis of the existing advanced transit technologies, and the results should be treated accordingly. Additionally, since the analysis was based only on a relatively small data sample, the reliability may not be particularly high and the results of the analysis should be treated with caution.

It is suggested to continue the efforts of collecting data from transit service providers on the performance and lifecycle costs of alternative fuel vehicles. As more field data are collected the reliability of the analysis will improve.

To facilitate data collection, CUTR recommends implementing a web-based reporting system that would allow agencies to input data electronically on a regular basis. It is also recommended that such data reporting becomes a requirement for transit agencies under their grant or funding agreements with FDOT. 


\section{References}

${ }^{1}$ Design Guidelines for Bus Transit Systems Using Electric and Hybrid Electric Propulsion as an Alternative Fuel, Federal Transit Administration, U.S. Department of Transportation, FTA-MA-26-707103-1, March 2003.

2 Guidebook for Evaluating, Selecting, and Implementing Fuel Choices for Transit Bus Operations, Federal Transit Administration, TCRP Report 38, 1998.

${ }^{3}$ Use of Alternative Fuels in Transit Buses, General Accounting Office, Resources, Community, and Economic Development Division, December 1999.

${ }^{4}$ Cost of Adding E-85 Fueling Capability to Existing Gasoline Stations: NREL Survey and Literature Search, National Renewable Energy Laboratory (NREL), NREL/FS-540-42390, March 2008.

${ }^{5}$ Analysis of Electric Drive Technologies for Transit Applications: Battery-Electric, Hybrid-Electric, and Fuel Cells, Federal Transit Administration, U.S. Department of Transportation, FTA-MA-26-7100-05-1, August 2005.

${ }^{6}$ Clean Air Program: Design Guidelines for Bus Transit Systems Using Hydrogen as an Alternative Fuel, Federal Transit Administration, U.S. Department of Transportation, FTA-MA-26-7021-98-1, October 1998.

${ }^{7}$ Alternative Fuel Transit Buses, Final Results from the National Renewable Energy Laboratory (NREL) Vehicle Evaluation Program, October 1996. 